\title{
2 Monitoring of group mates in relation to their activity in
}

\author{
3 mandrills
}

4

5 Short title: Social monitoring in mandrills

6

7

8 Gabriele Schino $^{1^{*}}$ and Martina Scerbo ${ }^{2}$

9

$10{ }^{1}$ Istituto di Scienze e Tecnologie della Cognizione, Consiglio Nazionale delle

11 Ricerche, Rome, Italy

$12{ }^{2}$ Dipartimento di Biologia Ambientale, Sapienza Università di Roma, Italy.

15 * Correspondence: Gabriele Schino: g.schino@istc.cnr.it 
Schino \& Scerbo, 2

\section{ABSTRACT}

Primates are known to have considerable knowledge about the social relationships that link their group mates, and are likely to derive this information from observing the social interactions that occur in their social group. They may therefore be hypothesized to pay particular attention to the social interactions involving group mates. In this study, we evaluated how the attention captive mandrills (Mandrillus sphinx) devote to their group mates was modulated by the behavior of the latter. Mandrills looked most frequently at foraging individuals and least frequently at sleeping invividuals. Mandrills also looked at grooming individuals more than at individuals that were simply sitting in contact. Grooming dyads were looked at regardless of the social rank and kinship of the individuals involved. These results contribute to our understanding of how primates obtain their social knowledge.

Key Words: Social cognition; Grooming, Attention; Mandrillus sphinx 
INTRODUCTION

In order to survive, primates need in-depth and updated knowledge

about their environment. Such knowledge can be aquired either individually or socially, by observing how group companions interact with potential sources of food or danger (Cook \& Mineka, 1990; Rapaport \& Brown, 2008). In order to compete successfully, primates also need updated knowledge about the social relationships that link their group mates. Indeed, research conducted in the last 40 years has shown that primates have considerable social knowledge. Not only are they aware of relatively stable characteristics of third-party social relationships such as dominance and friendships (reviews in Seyfarth \& Cheney, 2012, 2015), but they also appear to keep updated information on more transient phenomena such as sexual consortships, take-overs of onemale units, and postconflict reconciliation (Crockford et al., 2007; Judge \& Bachmann, 2013; le Roux \& Bergman, 2012). precluded to nonhuman primates, they must necessarily obtain their social

51 information individually and observationally. We know very little, however, about what aspects of the social life of their group mates they attend to. In one

53 of the few studies that addressed this issue, Tiddi et al. (2017) showed that

54 Japanese macaques (Macaca fuscata) did not obtain information about the kinship relationships of their group mates by remembering early mother-infant interactions, but seemed to keep an updated record of affiliative interactions occurring among group mates. They apparently relied on a rule of thumb that 
Schino \& Scerbo, 4

considered as related all dyads that exchanged frequent affiliation, and were thus unable to distinguish the kin from the "friends" of their group mates. If primates keep some sort of record of the interactions that occur among their group companions, we may hypothesize that they must pay particular attention to such interactions. The available information about how the attention primates pay to group mates is modulated by their behavior is scanty. A few studies showed primates (and non-primates) are interested in observing others engaged in ecologically relevant activities such as food manipulation or extraction (Ottoni et al., 2005; Range \& Huber, 2007; Scheid et al., 2007). Barbary macaques (M. sylvanus) have been shown to attend to scratching in others, possibly as a way to monitor their emotional state (Whitehouse et al., 2016). Bonobos (Pan paniscus), showed an attentional bias towards images of sexual or grooming behavior (Kret et al., 2016). Overall, it is clear that this is a subject that requires further investigation.

In this study, we first replicated previous analyses of the effects of dominance rank and kinship on attention paid to group mates (Schino \& Sciarretta, 2016). Then we evaluated how the attention paid by captive mandrills to their group mates is modulated by their activity. Given the obvious ecological relevance of finding food, we expected attention directed to foraging individuals to be high (although finding food may be less relevant in captivity). We hypothesized that mandrills would pay particular attention to the social interactions of group mates as a consequence of the need to monitor the state of their social relationships. We thus compared the attention paid to 
81 grooming individuals to that paid to individuals that are simply sitting in

82 contact, as well as the attention paid to individuals that are in proximity to a

83 group mate to that paid to lone individuals (see the Methods for details and

84 justification). We also expected that active individuals would attract more attention. We thus compared the attention paid to sleeping and awake group mates. Exploratory analyses tested whether the effects of dominance rank and

87 kinship was modulated by the activity of the target, and whether the attention paid to grooming was modulated by individual characteristics. Here, we hypothesized that rare grooming events should attract more attention than common grooming events.

METHODS

Ethical Note

This was a purely observational study conducted in a zoo setting. It complied with the Italian law, which requires no authorization for such studies, and with the American Society of Primatologists' principles for the ethical

97 treatment of non-human primates.

\section{Subjects and Housing}

The subjects of this study belonged to a captive group of mandrills living

101 in the Rome zoo (Bioparco). Initially, the group included two males and 10

102 females, but one male and one female died shortly after the beginning of data 
collection, and the few data that had been collected on them were discarded.

104 Details on the group composition can be found in Table 1.

105 The group lived in a $240 \mathrm{~m}^{2}$ outdoor enclosure connected with indoor

rooms. The enclosure was enriched with ropes, trunks and perches. Mandrills

were fed twice a day with vegetables, fruits, seeds and monkey chow. Seeds

were often dispersed in the substrate, and mandrills spent a considerable

amount of time searching for food. Water was available ad libitum.

111 Animals were arranged in a linear dominance hierarchy on the basis of

112 unidirectional dyadic aggressions using the I\&SI method as implemented in

113 DomiCalc (de Silva et al., 2017; Schmid \& de Vries, 2013). Further information on the subjects of this study can be found in Table 1.

\section{Data Collection}

118 three minutes. Each observation session had a subject and a target. The

119 observer recorded all glances directed by the subject to the target. We collected data on a single target for two reasons: first, we felt it would increase

121 the reliability of data collection (focusing on a single target is easier than having

122 to take into account all possible targets); second, our stringent criteria about

123 the visibility and activity of the target (see below) were impossible to be

124 monitored continuously on all possible targets. 
127 interaction (see below), this definition excludes the sustained looking associated with grooming or threatening. Since in primates staring directly at a target is often interpreted as a threat, glances directed at group mates are generally very brief. This is the reason most previous studies on social attention measured rates rather than durations. We followed this tradition.

132 Furthermore, being glances very brief, measuring their duration would be nearly impossible under the observational conditions of this study. Actual gaze direction (as revealed by eye movement) helped identify glances but was not always recognizable by the observer. Recording actual gaze direction in freely interacting animals is extremely difficult. That is why most previous studies resorted to definitions that included head orientation (see the Supporting Information in Allan \& Hill 2017). It is reasonable to assume that measuring head orientation as an estimate of gaze direction introduces noise but not bias in the data. member of the social group) had occurred in the previous 10 minutes. At the beginning of the observation session, the subject had to be awake and not

144 engaged in any social interaction. The target had to be visible by the subject, involved in one of the activities described in Table 2, and had to be at least $1 \mathrm{~m}$ away from the subject. 
Schino \& Scerbo, 8 not any more visible to the observer; the target was not any more visible to the subject; the subject was involved in any social interaction; an aggression occurred in the group; the target changed its activity, including a change in the direction of grooming; the distance between the subject and the target decreased to less than $1 \mathrm{~m}$. Observation sessions lasting less than $30 \mathrm{~s}$ were discarded. We were interested in (and analyzed) the effects of characteristics of the grooming dyad such as the difference in dominance rank between groomer and groomee. That is why we interrupted the observation session if the direction of grooming changed. Note also that: i) observation sessions were rather short (3 minutes) so that this sort of interruption occurred rarely; ii) there is no reason to suppose that interrupting observation sessions introduced any bias in the data.

A total of 4358 observation sessions were available for analysis (details in Tables 1 and 2). We were especially interested in the monitoring of the social interactions of group mates, and biased data collection accordingly (Table 2).

163 Our ability to obtain data was however constrained by the relative frequencies of the different behaviors so that, for example, sitting in contact was underrepresented in our sample. aggressive events (threats, chases and physical assaults) ad libitum. 
Schino \& Scerbo, 9

170

171

172

173

174

175

176

177

178

179

180

181

182

183

184

185

186

187

188

189

190

191

192

\section{Data analysis}

All our analyses were within-subject (fixed effect) conditional Poisson regressions with bootstrap standard errors. Within-subject regressions allow the use of multiple data points per subject while avoiding pseudoreplication. In within-subject regressions, each individual is compared only with itself (similarly to a paired sample t test), so as to exclude the effects of unknown and unmeasured variables and avoid the confusion between within-subject and between-subject effects (Allison, 2009; van de Pol and Wright, 2009). The dependent variable of all analyses was the count of glances recorded in each observation session (i.e., each observation session contributed one data point). The duration of the observation sessions was entered as an exposure variable. Independent variables included the rank of the target, the degree of maternal kinship between the subject and the target, and the activity of the target. The latter was entered as a dummy variable (i.e., as a set of six indicator variables each corresponding to one of the activities) and we assessed its significance using a Wald test that tested the null hypothesis that the effects of all the indicator variables were jointly zero. Pairwise comparisons of the effects of the different activities of the target applied the Šidàk correction in order to control for repeated testing. Beside presenting all possible pairwise comparisons, we focused on specific pairs of activities comparing target behaviors that differed, as much as possible, in a single key aspect. In particular, we felt it important to compare behaviors that were comparable in terms of general activity level, as more 
active animals may simply be more conspicuous (see also below for a

with "Awake alone" and with "Proximity" (since our definition of Foraging did

not specify whether the target should be alone or not). We compared

"Grooming" with "Sitting in contact", since both these contexts implied that

two animals were stationary and very close to each other. We compared

"Awake alone" with "Proximity" since for both contexts our definition did not present nearby. rate.

All statistical analyses were run on Stata 14.2 (StataCorp, 2015). ranking and at unrelated individuals (coeff.=-0.036, $\mathrm{Z}=-8.22, \mathrm{~N}=4358, \mathrm{P}<0.001$ 
and coeff. $=-0.262, \mathrm{z}=-3.05, \mathrm{~N}=4358, \mathrm{P}=0.002$, respectively). Controlling for

217 rank and kinship, the behavior of target affected potently the glance rate of the 218 subject (Wald test: $\chi^{2}=363.57, \mathrm{df}=5, \mathrm{P}<0.001$; Fig. 1 ). at by mandrills; specifically, it was looked at more than both "Awake alone" and "Proximity". Confirming our predictions, animals engaged in grooming were looked at more than animals that were simply sitting in contact to each other. Similarly, animals that were in proximity to a group mate were looked at more frequently than lone animals (compare "Proximity" with "Awake alone").

Finally, awake individuals were looked at more than sleeping individuals (compare "Awake alone" with "Sleeping alone"). target kinship were modulated by the behavior of the target, we repeated the first analysis presented above adding the interactions between target rank and target behavior and between subject-target kinship and target behavior. The interaction between target rank and target behavior was significant (Wald test: $\left.\chi^{2}=60.38, \mathrm{df}=5, \mathrm{P}<0.001\right)$, while that between subject-target kinship and target behavior was not ((Wald test: $\left.\chi^{2}=6.85, \mathrm{df}=5, \mathrm{P}=0.232\right)$. Analyses of the effect of target rank split by target behavior revealed that glance rate increased with increasing target rank for all behaviors examined but for grooming and sitting in contact (Fig. 2). Note that while the nonsignificant effect obtained for targets engaged in sitting in contact may be explained by the relatively small sample 
size, this is not a likely explanation for grooming, that had by far the largest sample size of all the activities we considered (Table 1).

Focusing on grooming, we analyzed the effects of the characteristics of the grooming dyad on the glances the subject directed to it. Neither the rank difference between groomer and groomee (coeff. $=0.010, z=0.75, N=1520$, $P=0.451$ ), nor their degree of kinship (coeff. $=0.206, z=0.97, N=1520, P=0.330$ ), nor their baseline frequency of grooming (coeff. $=-0.156, z=-0.11, N=1520$, $P=0.916)$ affected the glances they received from the subject.

\section{DISCUSSION}

The results of this study show that the behavior of group mates is a potent modulator of the attention mandrills pay to them. Mandrills looked most often at foraging individuals and showed particular interest for individuals involved in social interactions. Mandrills also differentiated sleeping from awake individuals, showing that they were sensitive to rather subtle differences in the behavior of their group mates.

A previous study showed mandrills devoted particular attention at individuals that had recently been involved in a fight (individuals that are also known to be particularly likely to redirect aggression to bystanders; Schino \& Marini, 2012; Schino \& Sciarretta, 2016). In the same vein, in this study more glances were directed at high-ranking and at unrelated individuals (see also Emory, 1976; Pitcairns, 1976), and very little glances were directed at sleeping individuals (that presumably present very little danger). These observations are 
coherent with field studies reporting a greater attention devoted to potentially 1998). Generally speaking, one of the functions of monitoring group mates seems to be the detection and possibly the anticipation of the risk of aggression, although in the field vigilance against predators often makes the identification of social monitoring more difficult (Allan \& Hill, 2017; Treves, 2000). unrelated individuals more than at their kin stands in direct contrast with the results of a previous study on the same social group (Schino \& Sciarretta, 2016). While it is difficult to find an explanation for this discrepancy, it should be noted that the two studies differed somewhat in the group composition (in the previous study several subadult, natal males were present), in the data collection procedure (in the previous study observation sessions had two

276 targets instead of one, and the target activity was not controlled) and in the

277 data analysis (in the previous study averages per dyad, rather than individual

278 observation sessions, were the unit of analysis). None of these differences stands as an obvious candidate for explaining the different results obtained about the effect of kinship on glance rate. At any rate, the differences between

281 the results of these two studies highlight that patterns of social attention may in some cases be sensitive to methodological details that appear of minor importance (see also Allan \& Hill 2017). It should however also be noted that other patterns of social attention seem in contrast to be extremely robust even 
in the face of interspecific and methodological differences. In fact, our

ranking individuals is consistent with several previous studies conducted both

by us and by others (Emory, 1976; Keverne et al., 1978; Pitcairns, 1976; Schino

\& Sciarretta, 2016).

foraging individuals suggests that, even in a captive environment, group mates

may constitute an important source of ecologically relevant information.

Clearly, in captivity the degree to which foraging group mates attract attention

is likely to depend on the details of the routine of food administration. When same place.

group mates. Very little comparable information is available in the literature, a

biased their attention towards pictures of grooming and sexual behavior.

304 Whether this is a general primate pattern remains to be ascertained.

305 Intriguingly, in mandrills grooming individuals were looked at irrespective of 
individuals, grooming low-ranking individuals were looked at as much as of the rank difference between groomer and groomee, of their kinship, and

311 (contrary to our expectations) of their baseline frequency of grooming (that is,

312 rare grooming events were not looked at more than common events).

313 Grooming seemed to be always equally interesting. The general attention paid to grooming cannot be explained in terms of the need to monitor potentially dangerous situations, as grooming individuals

316 do not constitute an impending threat. In contrast, the interest shown towards

317 grooming individuals is likely to derive from the need to monitor and update the

318 information about social relationships among group mates. Primates may need

319 an unbiased estimate of the grooming interactions occurring among group mates and, accordingly, mandrills did not bias their attention towards any

321 particular class of grooming dyads. It is also interesting to note that mandrills differentiated between grooming and sitting in contact. Although human observers often conflate grooming and passive contact as indicators of general affiliation (e.g., Silk et al., 2013), these two behaviors imply different costs and benefits and seem to be regarded by monkeys themselves as differentially worth of attention. the acquisition of valuable social and ecological knowledge. Primates are known to use in agonistic contexts the social knowledge they derive from 
331 monitoring group mates (Perry et al., 2004; Schino et al., 2006), although we

332 still have very little evidence that this social knowledge actually has positive

333 functional consequences (Tiddi et al., 2017). Elucidating the fitness consequences of variation in social knowledge seems thus to be an important research priority for future studies.

ACKNOWLEDGEMENTS colony, and Giorgio Manzi for his support. Sarah Brosnan and two anonymous reviewers provided constructive criticism.

DATA AVAILABILITY STATEMENT

\section{REFERENCES}

Allan, A. T. L., \& Hill, R. A. (2018). What have we been looking at? A call for consistency in studies of primate vigilance. American Journal of Physical Anthropology, 165, 4-22. http://doi.org/10.1002/ajpa.23381

Allison, P. D. (2009). Fixed effects regression models. Los Angeles: Sage.

350 Cook, M., \& Mineka, S. (1990) Selective associations in the observational conditioning of fear in rhesus monkeys. Journal of Experimental 
354 Crockford, C., Wittig, R. M., Seyfarth, R. M., \& Cheney, D. L. (2007). Baboons

355

356

357

358

359

360

361

362

363

364

365

366

367

368

369

370

371

372

373

374

375 eavesdrop to deduce mating opportunities. Animal Behaviour, 73, 885890. http://doi.org/10.1016/j.anbehav.2006.10.016

de Silva, S., Schmid, V. S., \& Wittemyer, G. (2017). Fission-fusion processes weaken dominance networks of female Asian elephants in a productive habitat. Behavioral Ecology, 28, 243-252. http://doi.org/10.1093/beheco/arw153

Emory, G. R. (1976). Aspects of attention, orientation, and status hierarchy in mandrills (Mandrillus sphinx) and gelada baboons (Theropithecus gelada). Behaviour, 59, 70-87.

Gaynor, K. M., \& Cords, M. (2012). Antipredator and social monitoring functions of vigilance behaviour in blue monkeys. Animal Behaviour, 84, 531-537. http://doi.org/10.1016/j.anbehav.2012.06.003

Judge, P. G., \& Bachmann, K. A. (2013). Witnessing reconciliation reduces arousal of bystanders in a baboon group (Papio hamadryas hamadryas). Animal Behaviour, 85, 881-889. http://doi.org/10.1016/j.anbehav.2013.02.011

Keverne, E. B., Leonard, R. A., Scruton, D. M., \& Young, S. K. (1978). Visual monitoring in social groups of talapoin monkeys (Miopithecus talapoin). Animal Behaviour, 26, 933-944.

Kret, M. E., Jaasma, L., Bionda, T., \& Wijnen, J. G. (2016). Bonobos (Pan paniscus) show an attentional bias toward conspecifics' emotions. 

available under aCC-BY-NC-ND 4.0 International license.

Schino \& Scerbo, 18

376

377

378

379

380

381

382

383

384

385

386

387

388

389

390

391

392

393

394

395

396

397

398

Proceedings of the National Academy of Sciences, 113, 3761-3766. http://doi.org/10.1073/pnas.1522060113

le Roux, A., \& Bergman, T. J. (2012). Indirect rival assessment in a social primate, Theropithecus gelada. Animal Behaviour, 83, 249-255. http://doi.org/10.1016/j.anbehav.2011.10.034

Ottoni, E. B., Dogo de Resende, B., \& Izar, P. (2005). Watching the best nutcrackers: What capuchin monkeys (Cebus apella) know about others' tool-using skills. Animal Cognition, 8, 215-219. http://doi.org/10.1007/s10071-004-0245-8

Perry, S., Barrett, H. C., \& Manson, J. H. (2004). White-faced capuchin monkeys show triadic awareness in their choice of allies. Animal Behaviour, 67, 165-170.

Pitcairns, T. K. (1976). Attention and social structure in Macaca fascicularis. In M. R. A. Chance \& R. R. Larsen (Eds.), The social structure of attention (pp. 51-81). New York: John Wiley \& Sons.

Range, F., \& Huber, L. (2007). Attention in common marmosets: implications for social-learning experiments. Animal Behaviour, 73, 1033-1041. http://doi.org/10.1016/j.anbehav.2006.07.015

Rapaport, L.G., \& Brown, G.R. (2008) Social influences on foraging behavior in young nonhuman primates: Learning what, where, and how to eat. Evolutionary Anthropology, 17, 189-201. doi: 10.1002/evan.20180

Scheid, C., Range, F., \& Bugnyar, T. (2007). When, what, and whom to watch? Quantifying attention in ravens (Corvus corax) and jackdaws (Corvus 
monedula). Journal of Comparative Psychology, 121, 380-386.

400 http://doi.org/10.1037/0735-7036.121.4.380

401 Schino, G., \& Marini, C. (2012). Self-protective function of post-conflict bystander affiliation in mandrills. PLOS ONE, 7, e38936. http://doi.org/10.1371/journal.pone.0038936

Schino, G., \& Sciarretta, M. (2016). Patterns of social attention in mandrills, Mandrillus sphinx. International Journal of Primatology, 37, 752-761. http://doi.org/10.1007/s10764-016-9936-7

Schino, G., Tiddi, B., \& Polizzi di Sorrentino, E. (2006). Simultaneous classification by rank and kinship in Japanese macaques. Animal Behaviour, 71, 1069-1074. http://doi.org/10.1016/j.anbehav.2005.07.019

410 Schmid, V. S., \& de Vries, H. (2013). Finding a dominance order most consistent with a linear hierarchy: an improved algorithm for the I\&SI method. Animal Behaviour, 86, 1097-1105. http://doi.org/10.1016/j.anbehav.2013.08.019

414 Seyfarth, R. M., \& Cheney, D. L. (2012). Knowledge of social relations. In J. C. Mitani, J. Call, P. M. Kappeler, R. A. Palombit, \& J. B. Silk (Eds.), The evolution of primate societies (pp. 628-642). Chicago: University of Chicago Press.

418 Seyfarth, R. M., \& Cheney, D. L. (2015). Social cognition. Animal Behaviour, 
420 Silk, J.B., Cheney, D.L., \& Seyfarth, R.M. (2013) A practical guide to the study

421

422

423

424

425

426

427

428

429

430

431

432

433

434

435

436

437

438

439

440 of social relationships. Evolutionary Anthropology, 22, 213-225. doi:

10.1002/evan.21367

StataCorp (2015). Stata: Release 14. Statistical software. College Station: StataCorp.

Tiddi, B., Polizzi di Sorrentino, E., Fischer, J., \& Schino, G. (2017). Acquisition and functional consequences of social knowledge in macaques. Royal Society Open Science, 4, 160639. http://doi.org/10.1098/rsos.160639

Treves, A. (2000). Theory and method in studies of vigilance and aggregation. Animal Behaviour, 60, 711-722. http://doi.org/10.1006/anbe.2000.1528

van de Pol, M., \& Wright, J. (2009). A simple method for distinguishing withinversus between-subject effects using mixed models. Animal Behaviour, 77, 753-758.

Watson, K. K., Li, D., Brent, L. J. N., Horvath, J. E., Gonzalez-Martinez, J., Ruíz-Lambides, A. V, Robinson, A. G., Skene, J. H. P., \& Platt, M. L. (2015). Genetic influences on social attention in free-ranging rhesus macaques. Animal Behaviour, 103, 267-275. http://doi.org/10.1016/j.anbehav.2015.02.012

Watts, D. P. (1998). A preliminary study of selective visual attention in female mountain gorillas (Gorilla gorilla beringei). Primates, 39, 71-78. http://doi.org/10.1007/BF02557744 
bioRxiv preprint doi: https://doi.org/10.1101/810440; this version posted October 18,2019 . The copyright holder for this preprint (which was not certified by peer review) is the author/funder, who has granted bioRxiv a license to display the preprint in perpetuity. It is made available under aCC-BY-NC-ND 4.0 International license.

Schino \& Scerbo, 21

441 Whitehouse, J., Micheletta, J., Kaminski, J., \& Waller, B. M. (2016). Macaques attend to scratching in others. Animal Behaviour, 122, 169-175.

443 http://doi.org/10.1016/j.anbehav.2016.10.020

444 
Table 1. Subjects of the study.

\begin{tabular}{|l|l|l|l|l|l|}
\hline Name & Sex & Rank & Matriline & $\begin{array}{l}\text { Observation } \\
\text { sessions as } \\
\text { subject }\end{array}$ & $\begin{array}{l}\text { Observation } \\
\text { sessions as } \\
\text { target }\end{array}$ \\
\hline Bart & m & 1 & b & 302 & 374 \\
\hline Beta & f & 10 & b & 442 & 262 \\
\hline Blanca & f & 2 & b & 407 & 564 \\
\hline Bunni & f & 3 & b & 463 & 403 \\
\hline Genni & f & 7 & g & 508 & 552 \\
\hline Giorgia & f & 8 & g & 499 & 485 \\
\hline Giulia & f & 5 & $\mathrm{~g}$ & 410 & 468 \\
\hline Greta & f & 6 & $\mathrm{~g}$ & 445 & 321 \\
\hline Irene & f & 4 & $\mathrm{~g}$ & 481 & 593 \\
\hline Malinka & $\mathrm{f}$ & 9 & $\mathrm{~m}$ & 401 & 336 \\
\hline
\end{tabular}


Table 2. Behaviors of target considered in this study.

\begin{tabular}{|c|c|c|}
\hline Behavior & Definition & $\begin{array}{l}N^{\circ} \text { of observation } \\
\text { sessions }\end{array}$ \\
\hline Awake alone & $\begin{array}{l}\text { Sitting or standing with eyes open; no } \\
\text { other individual is within } 2 \mathrm{~m}\end{array}$ & 508 \\
\hline Foraging & Eating or searching in the substrate & 683 \\
\hline Grooming & $\begin{array}{l}\text { Careful picking and/or slow brushing of } \\
\text { another monkey's fur using the hands } \\
\text { and/or the mouth; if interrupted for } \\
\text { more than } 15 \mathrm{~s} \text { it is considered } \\
\text { terminated; both grooming given and } \\
\text { grooming received are included }\end{array}$ & 1525 \\
\hline Proximity & $\begin{array}{l}\text { Being within } 1 \mathrm{~m} \text { of another individual } \\
\text { (but not in contact) }\end{array}$ & 1101 \\
\hline Sleeping alone & $\begin{array}{l}\text { Sitting or lying with eyes closed; no } \\
\text { other individual is within } 2 \mathrm{~m}\end{array}$ & 416 \\
\hline Sitting in contact & $\begin{array}{l}\text { Sitting in physical contact with another } \\
\text { individual who is also sitting }\end{array}$ & 125 \\
\hline
\end{tabular}


Table 3. Glances directed at the target in relation to its behavior: pairwise comparisons.

\begin{tabular}{|c|c|c|c|c|c|c|}
\hline & $\begin{array}{l}\text { Awake } \\
\text { alone }\end{array}$ & Foraging & Grooming & Proximity & $\begin{array}{l}\text { Sleeping } \\
\text { alone }\end{array}$ & $\begin{array}{l}\text { Sitting in } \\
\text { contact }\end{array}$ \\
\hline $\begin{array}{l}\text { Awake } \\
\text { alone }\end{array}$ & & $\begin{array}{l}Z=-4.77 \\
P<0.001\end{array}$ & $\begin{array}{l}Z=-1.01 \\
P=0.997\end{array}$ & $\begin{array}{l}Z=-3.94 \\
P=0.001\end{array}$ & $\begin{array}{l}z=7.16 \\
P<0.001\end{array}$ & $\begin{array}{l}Z=4,53 \\
P<0.001\end{array}$ \\
\hline Foraging & $\begin{array}{l}Z=4.77 \\
P<0.001\end{array}$ & & $\begin{array}{l}Z=7.23 \\
P<0.001\end{array}$ & $\begin{array}{l}Z=2.46 \\
P=0.191\end{array}$ & $\begin{array}{l}Z=14.87 \\
P<0.001\end{array}$ & $\begin{array}{l}Z=6.72 \\
P<0.001\end{array}$ \\
\hline Grooming & $\begin{array}{l}z=1.01 \\
P=0.997\end{array}$ & $\begin{array}{l}Z=-7.23 \\
P<0.001\end{array}$ & & $\begin{array}{l}Z=-8.14 \\
P<0.001\end{array}$ & $\begin{array}{l}z=9.34 \\
P<0.001\end{array}$ & $\begin{array}{l}z=5.10 \\
p<0.001\end{array}$ \\
\hline Proximity & $\begin{array}{l}Z=3.94 \\
P=0.001\end{array}$ & $\begin{array}{l}Z=-2.46 \\
P=0.191\end{array}$ & $\begin{array}{l}Z=8.14 \\
P<0.001\end{array}$ & & $\begin{array}{l}Z=11.05 \\
P<0.001\end{array}$ & $\begin{array}{l}Z=7.71 \\
P<0.001\end{array}$ \\
\hline $\begin{array}{l}\text { Sleeping } \\
\text { alone }\end{array}$ & $\begin{array}{l}z=-7.16 \\
P<0.001\end{array}$ & $\begin{array}{l}z=-14.87 \\
P<0.001\end{array}$ & $\begin{array}{l}z=-9.34 \\
P<0.001\end{array}$ & $\begin{array}{l}z=-11.05 \\
P<0.001\end{array}$ & & $\begin{array}{l}z=-2.63 \\
P=0.120\end{array}$ \\
\hline $\begin{array}{l}\text { Sitting in } \\
\text { contact }\end{array}$ & $\begin{array}{l}z=-4,53 \\
P<0.001\end{array}$ & $\begin{array}{l}Z=-6.72 \\
P<0.001\end{array}$ & $\begin{array}{l}z=-5.10 \\
p<0.001\end{array}$ & $\begin{array}{l}Z=-7.71 \\
P<0.001\end{array}$ & $\begin{array}{l}z=2.63 \\
P=0.120\end{array}$ & \\
\hline
\end{tabular}




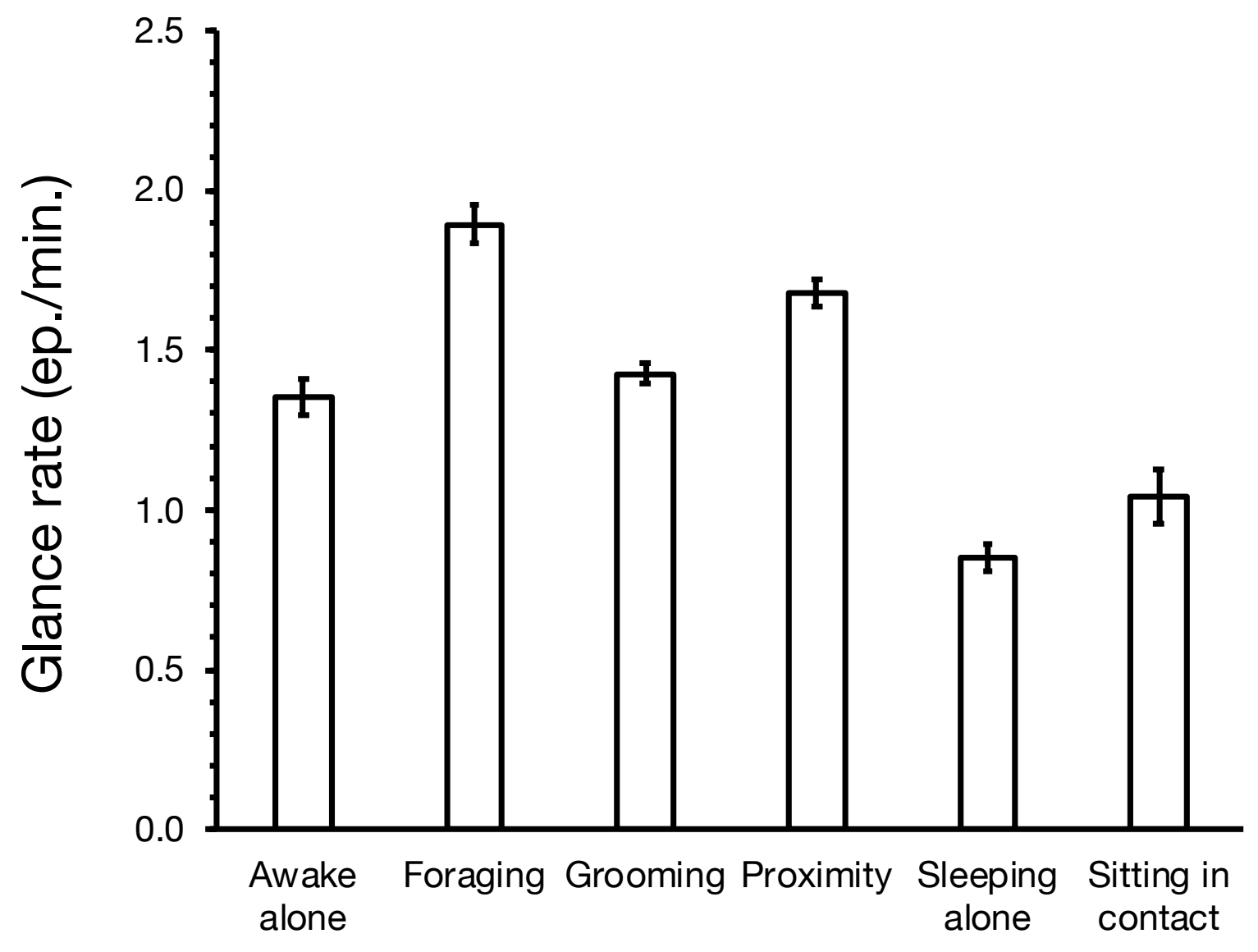

\section{Target behavior}

Figure 1. Effects of the target behavior on the rate of glances the subject directed to the target. Marginal means and standard errors, controlling for variation in the target dominance rank and in target-subject kinship. 


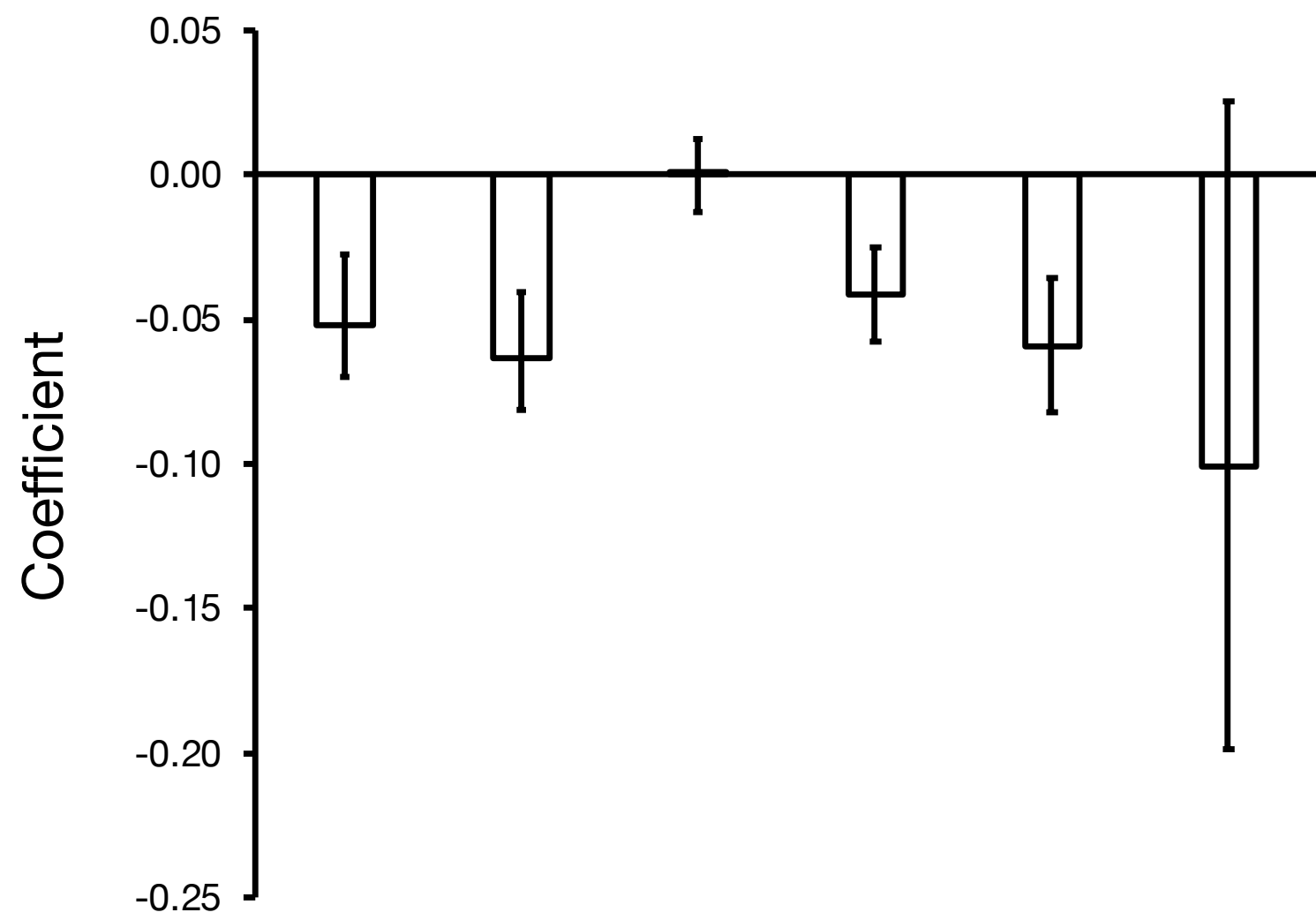

Awake Foraging Grooming Proximity Sleeping Sitting in alone alone contact

\section{Target behavior}

Figure 2. Effects of the target behavior on the relation between target rank and subject's glance rate. Coefficients of the separate Poisson regressions (and 95\% confidence intervals), controlling for target-subject kinship. 